\title{
Erratum to: Modeling the Microstructure Evolution During Additive Manufacturing of Ti6Al4V: A Comparison Between Electron Beam Melting and Selective Laser Melting
}

\author{
G. VASTOLA,${ }^{1}$ G. ZHANG, ${ }^{1,2}$ Q.X. PEI, ${ }^{1,3}$ and Y.-W. ZHANG ${ }^{1}$ \\ 1.-A*STAR Institute of High Performance Computing, 1 Fusionopolis Way \#16-16, Connexis, \\ Singapore 138632, Singapore. 2.—e-mail: zhangg@ihpc.a-star.edu.sg. 3.-e-mail: peiqx@ihpc. \\ a-star.edu.sg
}

Erratum to: JOM, Vol. 68, No. 5, 2016, pp. 1370-1375

DOI 10.1007/s11837-016-1890-5

This article was originally published without its electronic supplementary material. The ESM can be found here.

\section{ELECTRONIC SUPPLEMENTARY MATERIAL}

The online version of this article (doi:10.1007/s11837-016-1990-2) contains supplementary material, which is available to authorized users. 